\title{
BMJ Trends in adult cardiovascular disease open risk factors and their socio-economic patterning in the Scottish population 1995-2008: cross-sectional surveys
}

\author{
Joel W Hotchkiss, ${ }^{1}$ Carolyn Davies, ${ }^{1}$ Linsay Gray, ${ }^{1}$ Catherine Bromley, ${ }^{2}$ \\ Simon Capewell, ${ }^{3}$ Alastair H Leyland ${ }^{1}$
}

To cite: Hotchkiss JW, Davies C, Gray L, et al. Trends in adult cardiovascular disease risk factors and their socio-economic patterning in the Scottish population 1995-2008: cross-sectional surveys. BMJ Open 2011;1: e000176. doi:10.1136/ bmjopen-2011-000176

- Prepublication history for this paper is available online. To view these files please visit the journal online (http:// bmjopen.bmj.com).

Received 12 May 2011 Accepted 4 July 2011

This final article is available for use under the terms of the Creative Commons Attribution Non-Commercial 2.0 Licence; see http://bmjopen.bmj.com

${ }^{1} \mathrm{MRC} / \mathrm{CSO}$ Social and Public Health Sciences Unit, Glasgow, UK

${ }^{2}$ Scottish Centre for Social Research, Edinburgh, UK ${ }^{3}$ Division of Public Health University of Liverpool, Liverpool, UK

Correspondence to Dr Joel W Hotchkiss; joel. hotchkiss@sphsu.mrc.ac.uk

\section{ABSTRACT}

Objectives: To examine secular and socio-economic changes in cardiovascular disease risk factor prevalences in the Scottish population. This could contribute to a better understanding of why the decline in coronary heart disease mortality in Scotland has recently stalled along with a widening of socio-economic inequalities. Design: Four Scottish Health Surveys 1995, 1998, 2003 and 2008 (6190, 6656, 5497 and 4202 respondents, respectively, aged 25-64 years) were used to examine gender-stratified, age-standardised prevalences of smoking, alcohol consumption, physical activity, fruit and vegetable consumption, discretionary salt use and self-reported diabetes or hypertension. Prevalences were determined according to education and social class. Inequalities were assessed using the slope index of inequality, and time trends were determined using linear regression.

Results: There were moderate secular declines in the prevalence of smoking, excess alcohol consumption and physical inactivity. Smoking prevalence declined between 1995 and 2008 from $33.4 \%(95 \% \mathrm{Cl} 31.8 \%$ to $35.0 \%)$ to $29.9 \%(27.9 \%$ to $31.8 \%)$ for men and from $36.1 \%(34.5 \%$ to $37.8 \%$ ) to $27.4 \%$ (25.5\% to $29.3 \%)$ for women. Adverse trends in prevalence were noted for self-reported diabetes and hypertension. Over the four surveys, the diabetes prevalence increased from $1.9 \%(1.4 \%$ to $2.4 \%)$ to $3.6 \%(2.8 \%$ to $4.4 \%)$ for men and from $1.7 \%(1.2 \%$ to $2.1 \%)$ to $3.0 \%(2.3 \%$ to $3.7 \%)$ for women. Socio-economic inequalities were evident for almost all risk factors, irrespective of the measure used. These social gradients appeared to be maintained over the four surveys. An exception was self-reported diabetes where, although inequalities were small, the gradient increased over time. Alcohol consumption was unique in consistently showing an inverse gradient, especially for women.

Conclusions: There has been only a moderate decline in behavioural cardiovascular risk factor prevalences since 1995, with increases in self-reported diabetes and hypertension. Adverse socio-economic gradients have remained unchanged. These findings could help explain the recent stagnation in coronary heart disease mortalities and persistence of related inequalities.

\section{ARTICLE SUMMARY}

Article focus

- In Scotland, as in other developed countries, coronary heart disease mortality has declined substantially over time.

- This decline may now be slowing among younger groups, and there are still large inequalities in mortality between socio-economic groups.

- This study examined secular and socio-economic changes in cardiovascular disease risk factor prevalences in the Scottish population.

Key messages

- In Scotland, over a 13-year period since 1995 there have been at best only moderate declines in the prevalence of behavioural risk factors and no change in their socio-economic patterning, notably for smoking and poor diet.

- There has, however, been an increase in selfreported conditions predisposing to cardiovascular disease.

- This threatens to maintain inequalities in coronary heart disease mortalities and stifle further declines in mortality.

Strengths and limitations of this study

- This study utilised data from nationally representative surveys conducted over a 13-year period.

- The declining response levels to these surveys are of concern, possibly introducing bias. However, differential non-response by the socioeconomically disadvantaged may lead to an underestimation of the magnitude of inequalities.

\section{INTRODUCTION}

In Scotland, as elsewhere, coronary heart disease (CHD) mortality decreased rapidly from the 1970 s to the 1990 s. $^{1}$ Despite this, Scotland continues to have CHD mortalities among the highest in Europe. ${ }^{2}$ Approximately $60 \%$ of this decline has been attributed to riskfactor reduction; the remainder being predominately ascribed to improvements in medical treatments. ${ }^{3-5}$ Between 1986 and 
2006, this steady fall continued for older age groups. But from 1994, mortalities slowed, or even stopped, for individuals under 55 years. ${ }^{6}$ Similar plateauing in CHD mortalities has been identified in the USA, Australia, and England and Wales. ${ }^{7-9}$

Fifteen per cent of Scotland's 5 million population is income-deprived, and this deprivation is not evenly distributed, for example, in the City of Glasgow a quarter of the population experiences income deprivation. ${ }^{10} \mathrm{In}$ many countries, there is a steep socio-economic gradient across CHD mortality that has persisted. ${ }^{11-13}$ Furthermore, evidence for widening inequalities has been reported in the USA, Europe and Scotland. ${ }^{6}$ Much of the excess CHD associated with the socio-economically disadvantaged can be explained by the corresponding patterning in cardiovascular disease (CVD) risk factors, particularly smoking. ${ }^{1415}$

In this paper, we therefore investigate CVD risk factor prevalences according to socio-economic measures in Scotland between 1995 and 2008 using the Scottish Health Surveys (SHeSs). This might provide some explanation for these worrying trends in CHD mortality. External changes in socio-economic measurement practices have prevented the SHeSs reporting such indices consistently over time. ${ }^{16-19}$ We therefore now focus on the socio-economic patterning of behavioural CVD risk factors and self-reported CVD-related health measures according to two consistently available measures: educational level and social class.

\section{METHODS}

\section{Survey method and sample}

The 1995, 1998, 2003 and 2008 SHeSs are crosssectional, nationally representative surveys reporting the health and health-related behaviours (with emphasis on CVD) of people living in private households in Scotland; details are described elsewhere. ${ }^{16-19}$ The samples were selected using a multistage stratified clustered probability sampling design. Data were collected by face-toface interviews. The 2008 survey was part of a continuous survey running until 2011, utilising a smaller sample size than previously. The interview response proportion declined from $81 \%$ in 1995 to $54 \%$ in 2008 . The surveys were age-limited in 1995 (16-64 years) and in 1998 (2-74 years). Analyses were restricted to individuals aged between 25 and 64 years at the time of interview giving sample sizes that fell from 6910 in 1995 to 4202 in 2008 (table 1). The lower age limit was adopted because educational achievement is believed to be relatively stable by this age. The upper limit was dictated by the 1995 survey.

\section{Risk factors}

Risk factors were dichotomised with respondents having, or not having, the factor. Cigarette smokers were defined as respondents who currently smoked cigarettes. The consumption of alcohol by type, frequency and volume in the previous 12 months was converted into alcoholic units per week (one alcoholic unit $=10 \mathrm{ml}$ of ethanol).
Excessive drinkers were classed as those exceeding the UK recommended weekly limits (men $>21$, women $>14$ units/week).$^{20}$ A revised conversion method employed for 2003 and 2008 data precluded inclusion of the earlier surveys. ${ }^{21}$ Wine-glass size was only recorded in 2008.

Whether or not respondents complied with the UK government's recommendations on physical activity was recorded from 1998. The recommendations entail five or more occasions per week of at least moderate activity, for a total of at least $30 \mathrm{~min} /$ day. $^{22}{ }^{23}$ Contributing activities included those performed at home (housework, gardening, DIY, etc) and at work, as well as sport, exercise and walking. Activities performed for longer than 15 min contributed to the total.

Discretionary salt use was split into 'yes' or 'no' to the question 'At the table do you generally add salt to your food without tasting it first?' Low fruit and vegetable consumption was defined as eating less than five portions of either a day and was limited to the last two surveys. Self-reported diabetes and hypertension were recorded only if a doctor had informed respondents of the diagnosis. This was irrespective of treatment and was excluded if associated with pregnancy.

\section{Socio-economic measures}

Occupational social class (Registrar General's) was divided into seven categories I, II, III non-manual, III manual, IV, V and others (including armed forces/ unknown). In 2003 and 2008, it was derived from the National Statistics Socio-Economic Classification (NSSEC). ${ }^{24}$ The highest educational qualification that respondents achieved was divided into four levels: no qualifications, level 1: age at end of compulsory schooling $=16$ years from 1971, 15 years from 1947 and 14 years prior to 1947 (O grade, standard grade, GCSE or equivalent), level 2 (higher grade, A level, GSVQ advanced or equivalent and HNC, HND, SVQ Levels 4 or 5 or equivalent) and level 3 (first degree, higher degree or professional qualification, eg, teaching or accountancy). Between each survey, there was a slight variation in the questions used to determine educational attainment to reflect changes in the education system.

\section{Statistical analyses}

The prevalence of each risk factor was determined for the period 1995 to 2008 according to social class or education; participants in the 'other' categories were excluded (table 1). Respondents with missing data were only excluded from analyses of the affected risk factor. Survey weights were used to adjust for disproportionate sampling, differing selection probabilities and differential non-response. Gender-stratified prevalences were age-standardised (direct method) to the European standard population. ${ }^{25}$ For each risk factor and survey year, the slope index of inequality (SII) was estimated using the weighted least-squares method. The SII is the linear regression coefficient for the relationship between 
Table 1 Characteristics of the 1995, 1998, 2003 and 2008 Scottish Health Surveys

\begin{tabular}{|c|c|c|c|c|}
\hline & \multicolumn{4}{|c|}{ Scottish Health Survey } \\
\hline & 1995 & 1998 & 2003 & 2008 \\
\hline Sample size, $\mathrm{n}$ & 6910 & 6656 & 5497 & 4202 \\
\hline Mean age (SD) & 43.3 (11.6) & 43.8 (11.3) & $45.3(10.9)$ & $46.0(11.0)$ \\
\hline \multicolumn{5}{|l|}{ Gender, n (\%) } \\
\hline Men & $3049(44.1)$ & $2969(44.6)$ & $2437(44.3)$ & $1839(43.8)$ \\
\hline Women & 3861 (55.9) & $3687(55.4)$ & $3060(55.7)$ & $2363(56.2)$ \\
\hline \multicolumn{5}{|l|}{ Ethnicity, n (\%) } \\
\hline White & 6852 (99.2) & $6571(98.7)$ & $5357(97.5)$ & $4066(96.8)$ \\
\hline Other & $55(0.8)$ & $70(1.1)$ & $103(1.9)$ & $117(2.8)$ \\
\hline Missing & $3(0.0)$ & $15(0.2)$ & $37(0.7)$ & $19(0.5)$ \\
\hline \multicolumn{5}{|l|}{ Cigarette smoking, $\mathrm{n}(\%)$} \\
\hline Non-smoker & $4379(63.4)$ & $4231(63.6)$ & $3786(68.9)$ & 3038 (72.3) \\
\hline Current smoker & $2531(36.6)$ & 2417 (36.3) & $1687(30.7)$ & $1155(27.5)$ \\
\hline Missing & & $8(0.1)$ & $24(0.4)$ & $9(0.2)$ \\
\hline \multicolumn{5}{|l|}{ Alcohol, n (\%)* } \\
\hline$\leq$ Weekly limits & - & - & $3805(69.2)$ & $3122(74.3)$ \\
\hline$>$ Weekly limits & - & - & $1647(30.0)$ & $1052(25.0)$ \\
\hline Missing & & & $45(0.8)$ & $28(0.7)$ \\
\hline \multicolumn{5}{|l|}{ Physical activity, n (\%)† } \\
\hline$\geq 5$ times a week & - & $2266(34.0)$ & $2066(37.6)$ & $1726(41.1)$ \\
\hline$<5$ times a week & - & $4381(65.8)$ & 3417 (62.2) & $2469(58.8)$ \\
\hline Missing & & $9(0.1)$ & $14(0.3)$ & $7(0.2)$ \\
\hline \multicolumn{5}{|l|}{ Fruit or vegetables, n (\%) } \\
\hline$\geq 5$ portions a day & - & - & $1296(23.6)$ & $1031(24.5)$ \\
\hline$<5$ portions a day & - & - & $3689(67.1)$ & $2829(67.3)$ \\
\hline Missing & & & $512(9.3)$ & $342(8.1)$ \\
\hline \multicolumn{5}{|l|}{ Salt use, $n(\%) \neq$} \\
\hline Don't add/taste first & $4771(69.0)$ & 4614 (69.3) & $4190(76.2)$ & $1210(82.8)$ \\
\hline Add without tasting & $2138(30.9)$ & $2035(30.6)$ & $1286(23.4)$ & $252(17.2)$ \\
\hline Missing & $1(0.0)$ & $7(0.1)$ & $21(0.4)$ & - \\
\hline \multicolumn{5}{|l|}{ Diabetes, n (\%)§ } \\
\hline No & $6771(98.0)$ & $6501(97.7)$ & 5349 (97.3) & $4051(96.4)$ \\
\hline Yes & $132(1.9)$ & $155(2.3)$ & $147(2.7)$ & $151(3.6)$ \\
\hline Missing & $7(0.1)$ & - & $1(0.0)$ & - \\
\hline \multicolumn{5}{|l|}{ Hypertension, n (\%)§ } \\
\hline No & $5703(82.5)$ & $5526(83.0)$ & $4422(80.4)$ & 3291 (78.3) \\
\hline Yes & $1142(16.5)$ & $1122(16.9)$ & $1058(19.2)$ & $908(21.6)$ \\
\hline Missing & $65(0.9)$ & $8(0.1)$ & $17(0.3)$ & $3(0.1)$ \\
\hline \multicolumn{5}{|l|}{ Social class, n (\%) } \\
\hline I Professional & 297 (4.3) & $280(4.2)$ & $316(5.7)$ & $225(5.4)$ \\
\hline II Managerial & $1644(23.8)$ & $1696(25.5)$ & $1646(29.9)$ & $1232(29.3)$ \\
\hline III NM Skilled non-manual & $1534(22.2)$ & $1404(21.1)$ & $1125(20.5)$ & $889(21.2)$ \\
\hline III M Skilled manual & $1424(20.6)$ & $1348(20.3)$ & $984(17.9)$ & $773(18.4)$ \\
\hline IV Semiskilled manual & $1111(16.1)$ & $1177(17.7)$ & $939(17.1)$ & $703(16.7)$ \\
\hline V Unskilled manual & $575(8.3)$ & $468(7.0)$ & $320(5.8)$ & $253(6.0)$ \\
\hline Other (armed forces, unknown) & $325(4.7)$ & $283(4.3)$ & $167(3.0)$ & $127(3.0)$ \\
\hline \multicolumn{5}{|l|}{ Education, n (\%) } \\
\hline Level 3 degree level or above & $1793(25.9)$ & $1727(25.9)$ & $1482(27.0)$ & $1177(28.0)$ \\
\hline Level 2 intermediate & $1043(15.1)$ & 1209 (18.2) & $1070(19.5)$ & $1046(24.9)$ \\
\hline Level 1 end of compulsory schooling & $1839(26.6)$ & $1723(25.9)$ & $1641(29.9)$ & $1156(27.5)$ \\
\hline No qualifications & 2226 (32.2) & $1978(29.7)$ & $1274(23.2)$ & $802(19.1)$ \\
\hline Other qualifications or missing & $9(0.1)$ & $19(0.3)$ & $30(0.5)$ & $21(0.5)$ \\
\hline
\end{tabular}


the prevalence of each risk factor in each socioeconomic category and the hierarchical ranking of each socio-economic group category on the social scale. ${ }^{26}$ Time trends for prevalence and the SIIs were assessed using generalised linear regression. All analyses were performed using the statistical software SAS (V. 9.2), and statistical significance was taken as $\mathrm{p}<0.05$.

\section{RESULTS}

The participants' mean age increased across the four surveys, from 43.3 years in 1995 to 46.0 years in 2008 (table 1). The proportion of women was greater than that of men in all the surveys. Over time, the population distribution shifted according to both socio-economic measures. In general, the proportion of individuals in the 'upper' strata (eg, managerial class or level 3 qualifications) increased compared with those in the 'lower' strata (eg, unskilled class or no qualifications).

Between 1995 and 2008, unadjusted, overall smoking prevalence fell from $36.6 \%$ to $27.5 \%$ (table 1). The proportion of smokers among men with no qualifications actually increased from $46.5 \%$ (95\% CI $43.1 \%$ to $50.0 \%)$ to $50.8 \%(44.5 \%$ to $57.1 \%)$ by 2008 , while among those with level 3 qualifications there had been a significant decrease from $19.0 \%(15.7 \%$ to $22.4 \%)$ to $14.7 \%$ ( $11.9 \%$ to $17.5 \%$ ) (table 2 ). Consequently, the SII increased for men from $32.7(\mathrm{p}=0.02)$ in 1995 to 42.1 $(p=0.04)$ in 2008 when stratified according to education. The proportion of women who smoked decreased irrespective of educational achievement, and the SII narrowed from $43.7(p=0.02)$ to $37.1(p=0.04)$, from the first to last survey. Stratification by social class identified similar patterns to education (table 3). For weekly alcohol consumption, the proportion exceeding recommended limits declined between 2003 and 2008 (tables 2, 3). A significant negative SII was present for women in both these surveys, except for by education in 2008. There were no significant SIIs for men.

In the 10 years from 1998, the proportion of men not achieving recommended physical activity levels declined from $60.5 \%(58.8 \%$ to $62.2 \%)$ to $51.2 \%(49.0 \%$ to $53.3 \%$ ) (table 3). A similar improvement occurred among women, falling from $68.6 \%(67.0 \%$ to $70.2 \%)$ to $62.5 \%(60.4 \%$ to $64.5 \%)$, albeit starting from a less favourable level. By social class, the negative SIIs for social class among men were significant or borderline significant, while for women the positive SIIs were small and non-significant. For education, significant SIIs were identified for 1998 and 2008 in women, with a borderline significant increase in the index over time (table 2). There were minimal social gradients for men.

For women, there were significant positive SIIs for lessthan-ideal fruit and vegetable intake for both socioeconomic measures (tables 4,5 ). The proportion of women not meeting recommendations decreased in most of these social and educational strata. In general, more men than women did not achieve recommended limits. Among men, there was little change over time. There were reductions over time, in the proportion of adults who added salt to their food at the table without first tasting it, irrespective of gender or socio-economic position (tables 4, 5). There were significant SIIs for the majority of survey years for both socio-economic measures.

Overall, there were significant linear increases in selfreported diabetes prevalence per year of $0.12 \%$ $(\mathrm{p}=0.03)$ for men and $0.10 \%(\mathrm{p}=0.04)$ for women; by 2008 , the prevalence for men is $3.6 \%$ (2.8\% to $4.4 \%)$ and for women $3.0 \%(2.3 \%$ to $3.7 \%$ ) (table 6$)$. When stratified by education, inequalities had increased by 2008 , in this year the $\mathrm{SII}=2.9(\mathrm{p}=0.03)$ for men and 5.0 $(\mathrm{p}=0.23)$ for women; among men, this represented a significant increase in the SII of 0.22 per year $(p=0.005)$. According to social class, the increase in socio-economic gradient was less consistent, but by 2008, it was steeper than in 1995 (table 7). The prevalence of self-reported hypertension, from the first to the last survey, increased from $17.0 \%$ ( $15.7 \%$ to $18.3 \%$ ) to $21.3 \%$ (19.7\% to $23.0 \%$ ) for men and from $16.5 \%$ (15.2\% to $17.7 \%$ ) to $18.5 \%$ (16.9\% to $20.0 \%$ ) for women (table 6 ). Socio-economic gradients existed according to both measures, and there had been no significant changes by 2008.

\section{DISCUSSION}

This study has investigated trends in the socio-economic patterning of selected CVD risk factors between 1995 and 2008 in the Scottish population. Although there were marginal overall reductions in most adverse behavioural risk factors, these were not evenly distributed across society. Where inequalities existed in 1995, there had been no discernible narrowing of the gap 13 years later. There was even a hint of widening in some cases, although this was not significant. Self-reported diabetes and hypertension also increased in prevalence over this time with worrying indications that this had occurred at a faster rate in the socio-economically disadvantaged.

Smoking is both a powerful CVD risk factor and the strongest contributor to socio-economic differences in CHD mortality in both Scottish and English populations. ${ }^{27}$ Smoking prevalence has a steep socio-economic gradient that has persisted, or worsened over time in Scotland, as in many countries. ${ }^{28-32}$ In this study, the picture was more encouraging for women with a declining prevalence for all groups with a marginal reduction in the socio-economic differential. However, sharper falls in smoking among UK non-manual groups have been reported elsewhere for men and women between 1998 and 2008, thereby widening the gap. ${ }^{33}$ It is probably premature to judge the effect on smoking prevalence of the 2006 ban on smoking in public indoor spaces introduced in Scotland. ${ }^{34}$ It may be naïve to hope that it will accelerate the moderate decline seen in this study.

The higher consumption of alcohol by women of higher socio-economic standing is frequently reported, ${ }^{33} 35$ including in Scotland. ${ }^{36}$ The latter mid- 


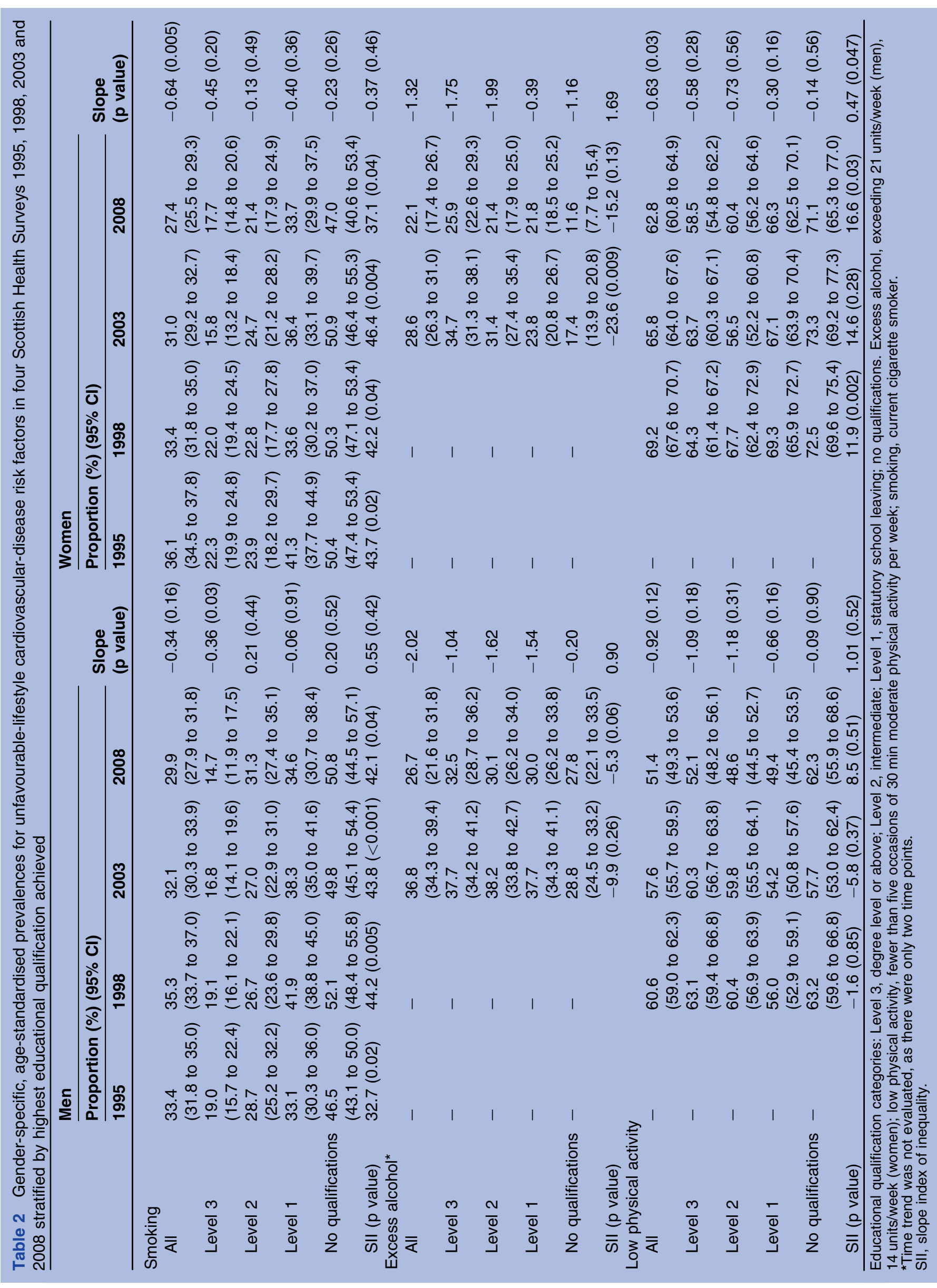




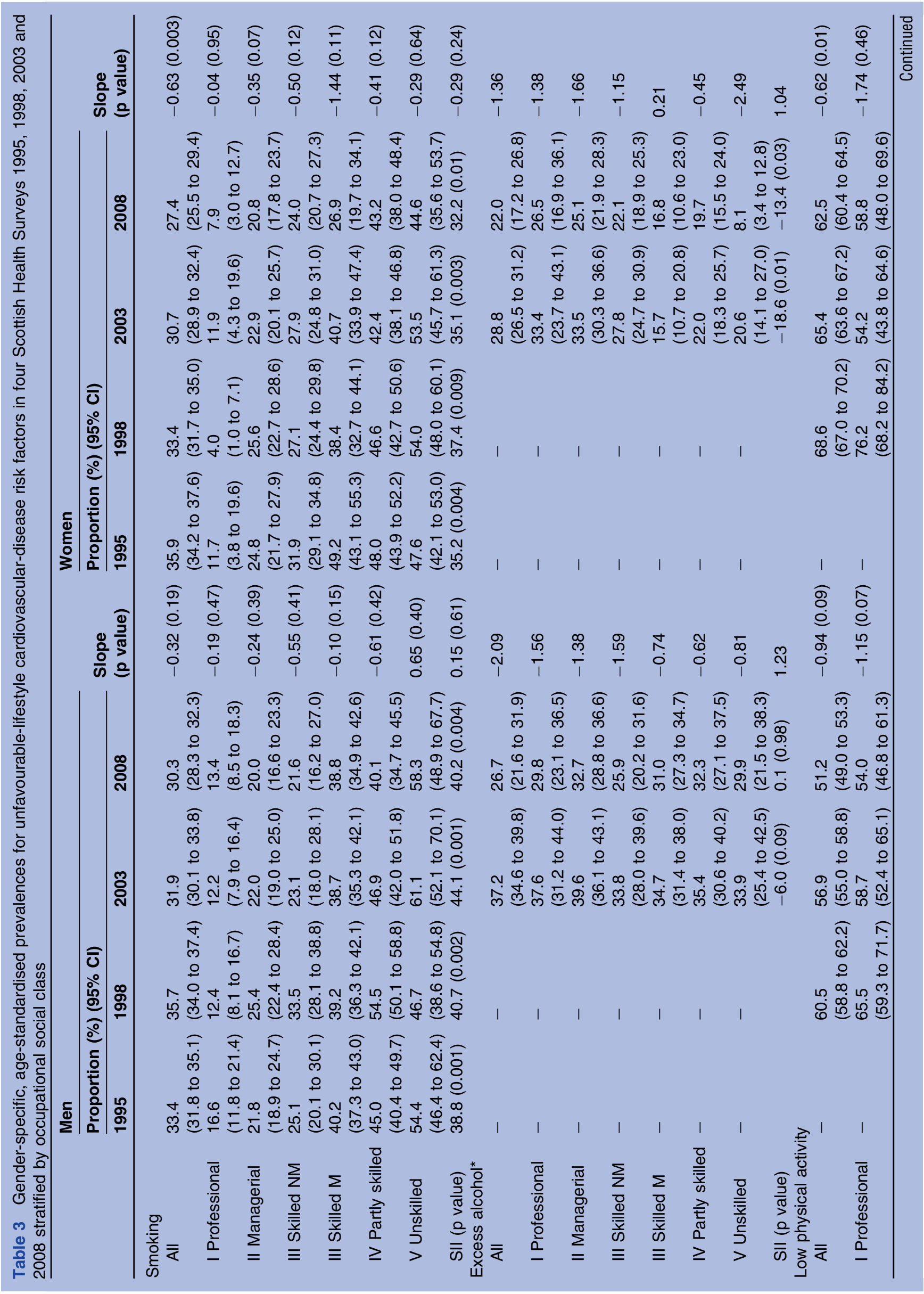




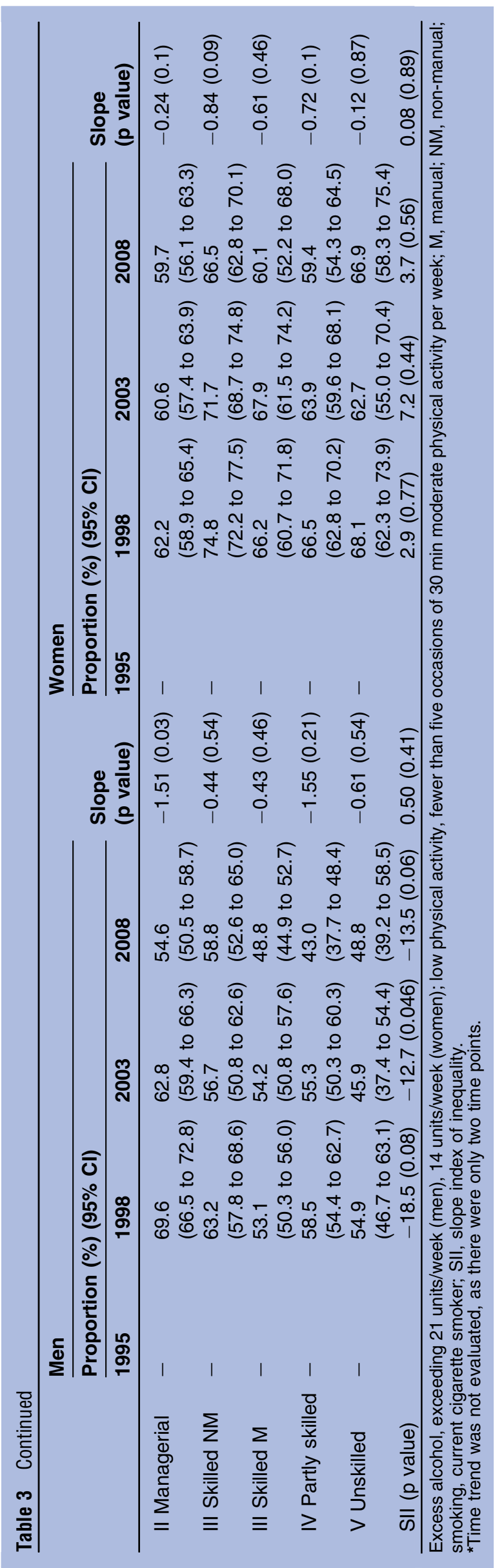

1980s study identified that male manual workers had heavier alcohol consumption as opposed to the absence of a pattern in our study. The use of a revised conversion method prevented use of the earlier surveys, in which alcohol consumption was probably underestimated. ${ }^{21}$ Some under-reporting of alcohol consumption is known to exist due to the pressure of social desirability and recall error, but self-reported measures are nevertheless believed to have some validity. ${ }^{37}$ Furthermore, biases common to all variables from the $\mathrm{SHeSs}$ could lead to heavy drinkers being under-represented.

Across all socio-economic groups, fewer people were falling short of recommended physical activity levels by 2008. However, the improvements were not dramatic. For women, we identified a physical activity gradient by education level. Physical activity has been shown to be an important explanatory variable for educational level differences in Finnish CVD mortality. ${ }^{38}$ Education did not differentiate between physical activity levels among men, but social class did, with the negative SII reflecting the physical nature of manual occupations. The 2003 Health Survey for England identified a similar gradient based on NS-SEC. ${ }^{39}$

Low fruit and vegetable consumption can be considered a proxy for a poor diet. Most affluent men and women more frequently consume a healthier diet in England, ${ }^{39}$ Australia ${ }^{29}$ and elsewhere. In this study, there had been minimal change in fruit and vegetable dietary habits over 5 years, despite the 'five a day' campaign in the UK. ${ }^{40}$ Not adding salt at the table may indicate an awareness of the associated health issues rather than reduced consumption.

The worrying increase in diabetes and hypertension prevalence could reflect the rise of obesity among the Scottish population. ${ }^{16}$ These variables were considered irrespective of treatment, as population changes were of interest. The rise in diabetes, with a widening socioeconomic gap, could be a warning that Scotland is replicating trends seen in England, the USA and Canada. $^{28} \quad 30 \quad 41 \quad 42$ Self-reported hypertension also increased in Canada, with a widening of socio-economic disparities. ${ }^{30}$ This could reflect persistent high dietary salt consumption (perhaps associated with processed food and fast food), distinct from the reduced discretionary salt use reported here. In the UK, discretionary salt intake has been reported to contribute only modestly to sodium intake, while processed foods contribute heavily to the total. ${ }^{43}$ The extent to which medical intervention may ameliorate this trend in hypertension is limited. ${ }^{44} \mathrm{~A}$ worrying increase in objectively measured hypertension has also been identified using the SHeSs, ${ }^{45}$ much as in the USA. ${ }^{46}$

The use of both education and social class as measures of socio-economic status should provide gains compared with using just one, particularly as they are not necessarily interchangeable. ${ }^{47}$ Alternative indices such as area of deprivation, income and NS-SEC were not consistently available across the surveys. The age of 


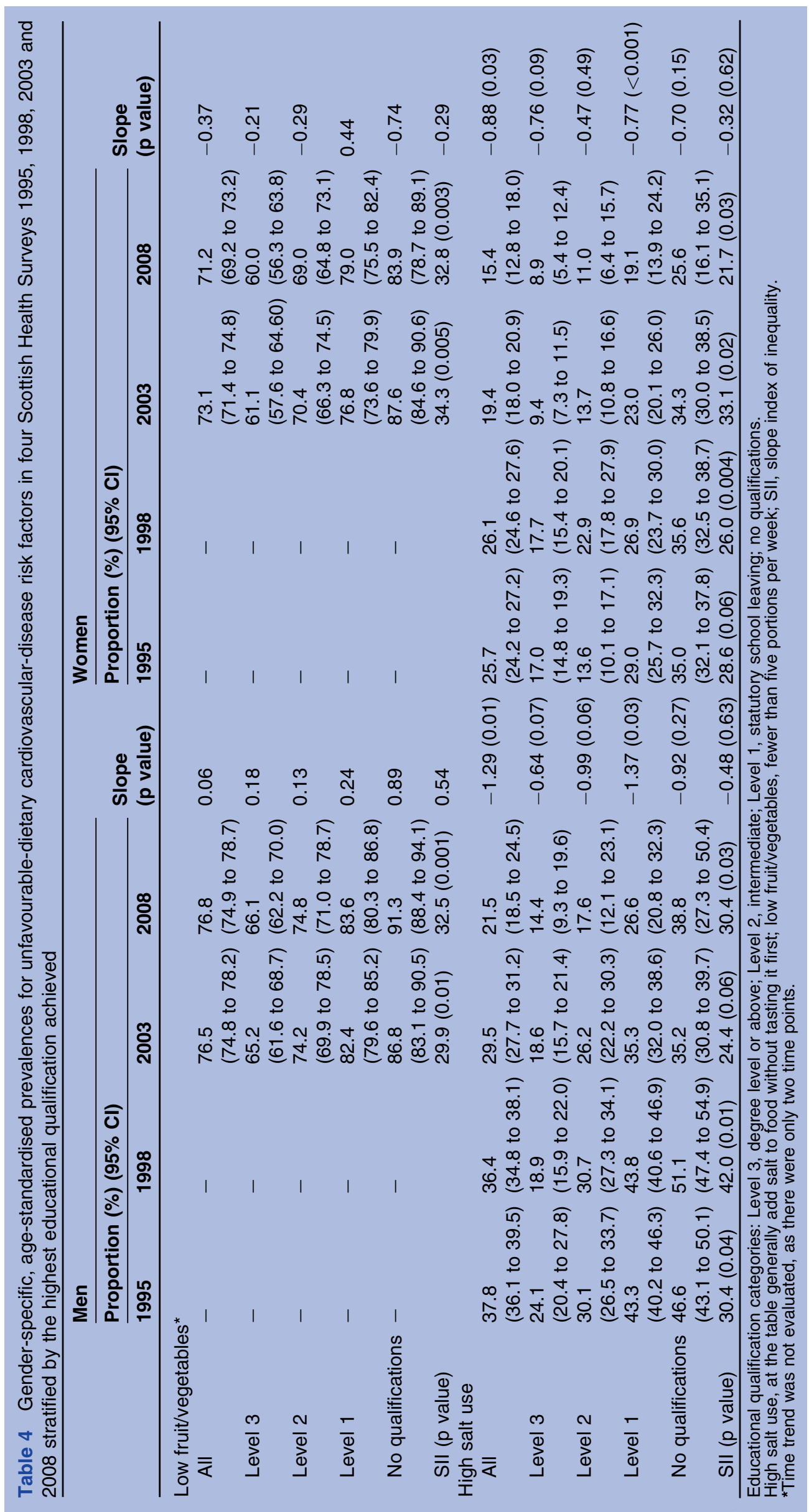




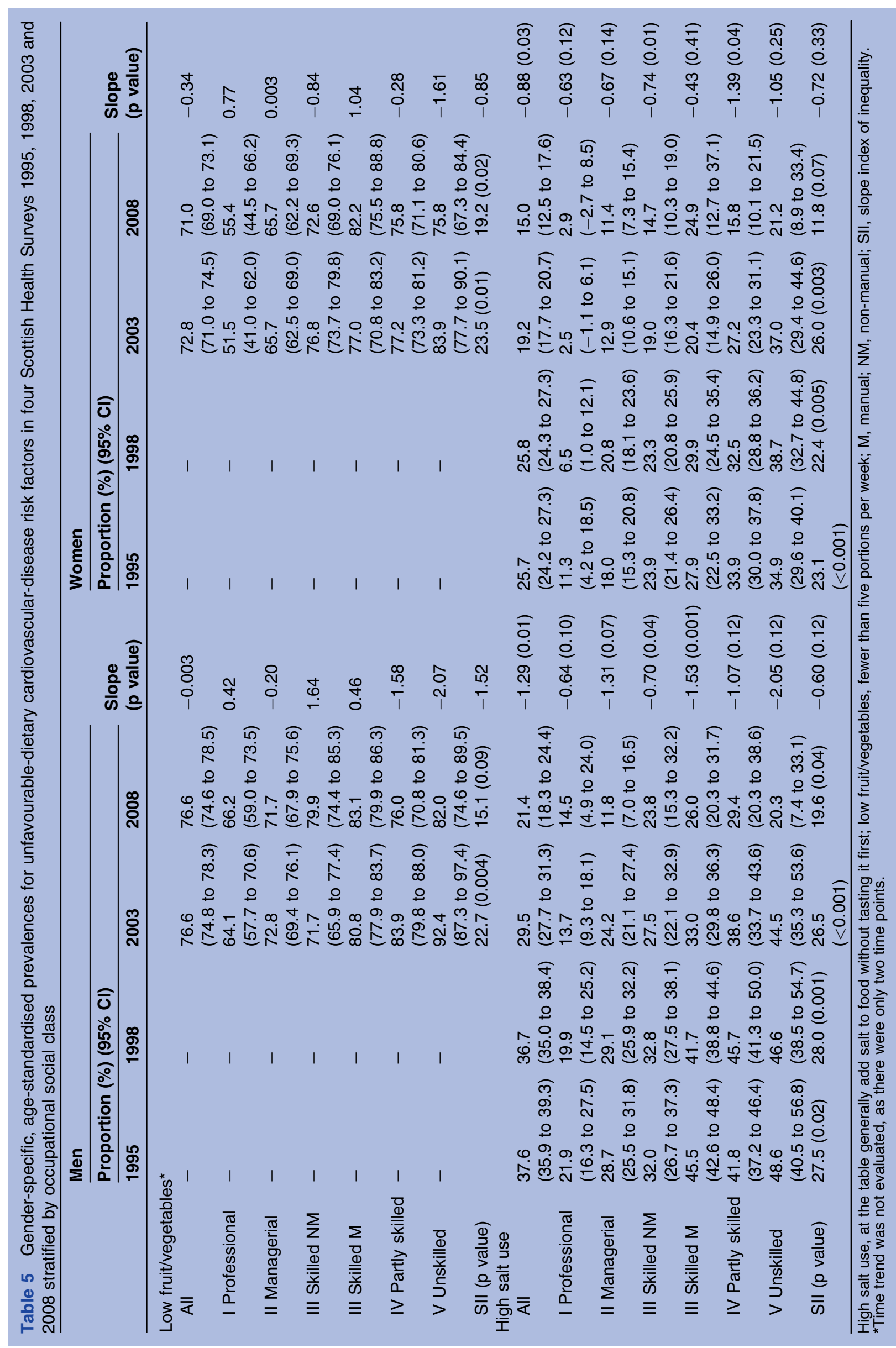




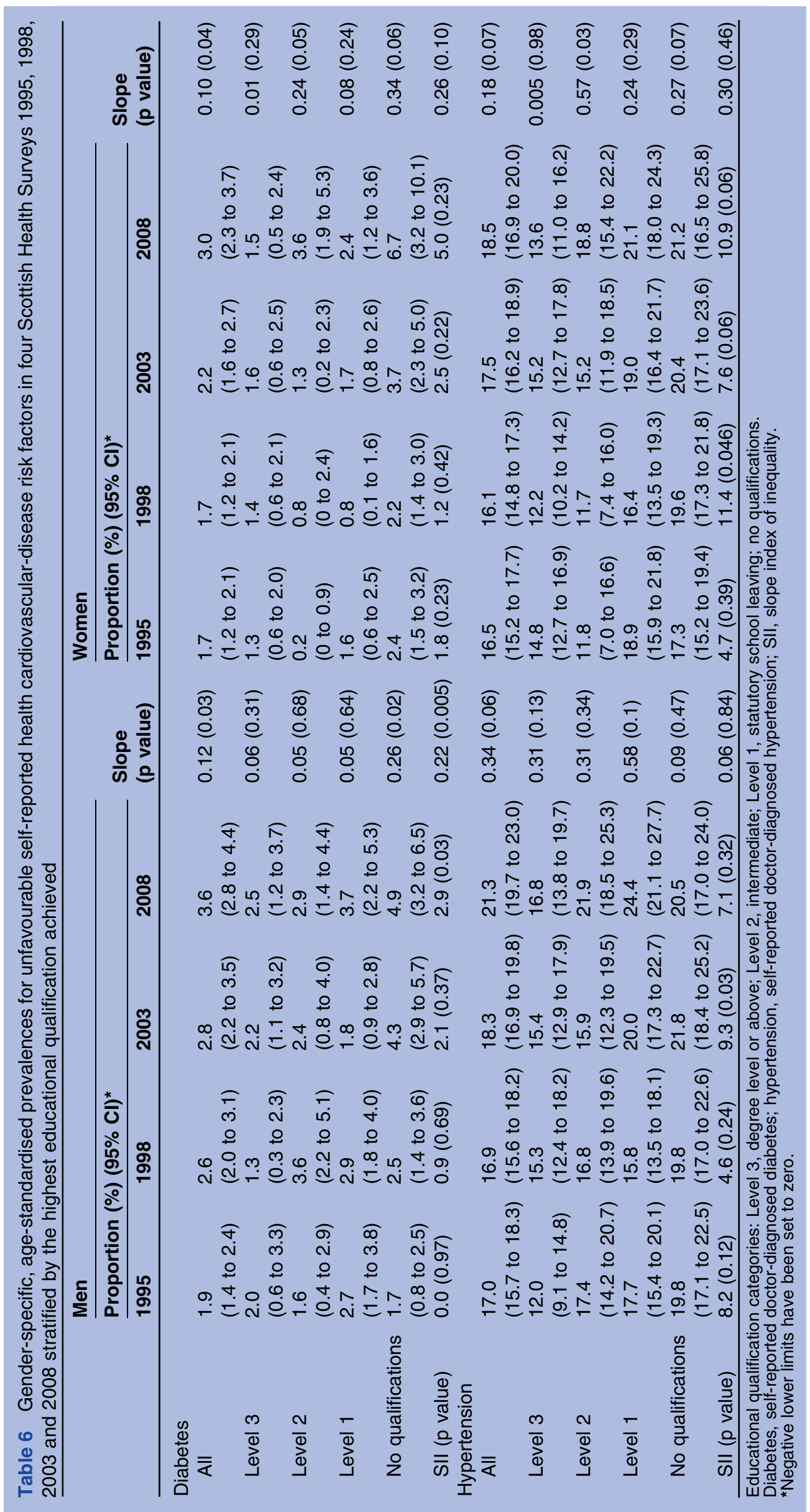




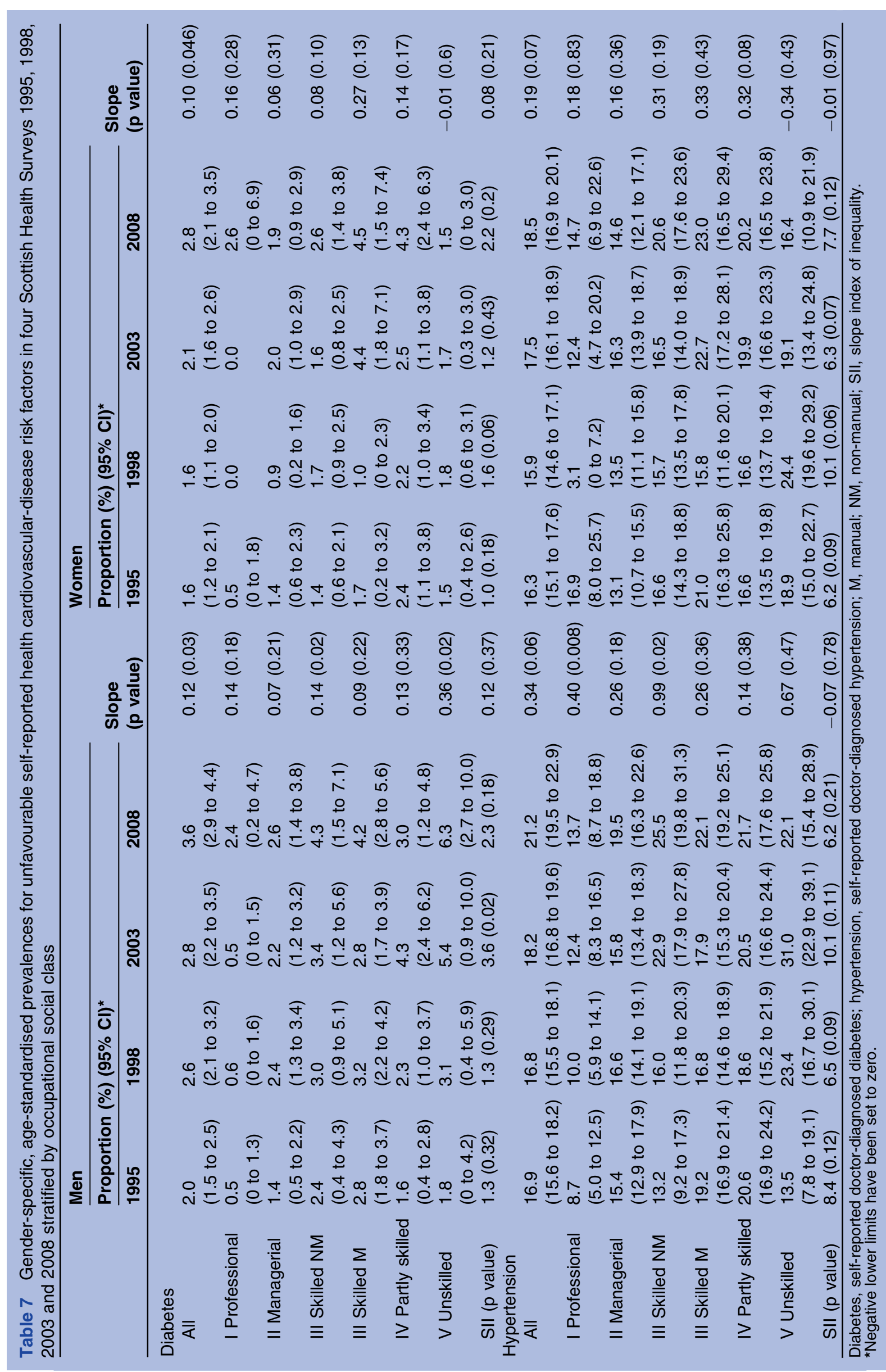


departure from education was available, but the highest qualification achieved was considered superior, as it accounted for further education later in life. Better education may provide the knowledge required to adopt healthier lifestyles and often facilitate a better occupation with a correspondingly higher income. The use of NS-SEC-derived social class in the last two surveys and the change in composition of social classes over time may have led to some of the observed alterations in riskfactor prevalence patterning. The low numbers in the highest and lowest categories, particularly for unskilled women, might have led to potentially volatile estimates.

One of this study's strengths is the use of data from nationally representative surveys. We also recognise a number of limitations. Only individuals living in private households were surveyed, excluding, for example, those in residential care, hostel dwellers, the military and students in residential halls. Feasibly, these communities may have different health behaviours from those surveyed. All of these risk factors are self-reported and therefore subject to recall bias and respondents' desire to falsely report sociably acceptable behaviour. The declining response levels in these surveys are of concern, possibly introducing bias. This problem is common across surveys in general. However, a switch to sampling multiple adults within households from 2003 probably contributed to the decline, as interviewers, after enrolling one individual, may have been disincentivised to pursue additional household members. Responders to health-examination surveys tend to be older, female and of a higher socio-economic class and to live a healthier lifestyle. ${ }^{49}$ Furthermore, the 2003 SHeS response was indeed modestly skewed towards those in less deprived areas. ${ }^{50}$ Conversely, some studies have suggested that such non-response biases can have minimal impact on prevalence estimates. ${ }^{51}{ }^{52}$ On balance, a differential response could lead to underestimates for most risk factors in the lower socio-economic groups, which suggests that true inequalities are even greater than those shown here.

The focus in this study was on health behaviours, partly because they causally precede many of the CVD biological risk factors. The limited range of factors considered, plus disparities in their contribution to overall risk, curtails the potential for explaining CHD mortality inequalities. Some researchers have noted an inability of risk factors to fully explain socio-economic differentials in CVD mortality. ${ }^{11} 53$ However, risk factors should not be considered in isolation, as they cluster within individuals, ${ }^{54}$ and the relative risks of CHD mortality has been shown to increase substantially with each additional factor. ${ }^{55}$ Lawder et al, using the 2003 SHeS, identified that $97.5 \%$ of the Scottish population had at least one of the following risk factors smoking, excessive alcohol consumption, poor diet, low physical activity or overweight/obesity. ${ }^{50}$ The socio-economically disadvantaged have been shown to be more likely to have multiple lifestyle risk factors. ${ }^{50} 56$ We therefore hope to consider biological risk factors and the impact of clustering in a future analysis.

It is not possible to assess the contribution of the myriad of interventions aimed at improving the Scottish population's health to the moderate declines, or to the changes in inequalities, seen in this study. Some critics might state that the sum effect has been limited, prompting the disparate arguments that future interventions should focus on legislative regulation (eg, smoke-free legislation ${ }^{34}$ ) or be less dictatorial (eg, the 'nudge' approach ${ }^{57}$ ), or be more focused on particular groups of individuals. We examined risk factors in those over 25 years of age where health behaviours will be well established. It is early in life that social inequalities have their greatest impact on determining persistent behaviours and health status. ${ }^{58-60}$ Consequently, it has been suggested that interventions should be early in life. ${ }^{61}$ Theoretically, interventions that result in small changes in risk-factor prevalence at the population level can have great gains in reducing CHD mortality. ${ }^{62}$ The time lag between changes in risk factors and changes in CHD mortality is now understood to be relatively short. ${ }^{64} 65$ For smoking cessation, it may be only a few months, ${ }^{66}$ and for population diets changes as little as 2 or 3 years. ${ }^{65}$ If social inequalities in CHD mortality are to be addressed, then interventions need to be targeted at the socio-economically disadvantaged. An effective solution might be to address the actual causes of social inequality rather than its downstream effects on risk factors. ${ }^{67}$ Whatever the approach to reducing risk factors in the future, it is obvious that much more needs to be done.

In conclusion, there has been minimal, or at best only moderate, decline in behavioural cardiovascular risk factor prevalences since 1995 . Over the same period, selfreported diabetes and hypertension have increased in prevalence. These findings could help explain the recent stagnation in CHD mortalities. Furthermore, the lack of change in the socio-economic gradients associated with these risk factors may ensure that inequalities in cardiovascular mortality remain entrenched in the Scottish population.

Funding The Social and Public Health Sciences Unit is jointly funded by the Medical Research Council and the Chief Scientist Office of the Scottish government Health Directorate. This research was funded by the Chief Scientist Office as part of the 'Measuring health, variations in health and determinants of health' programme, wbs U.1300.00.001.

Competing interests CB had support from the Scottish Government Health Directorates (for the Scottish Health Surveys 2008-2011), and LG had support from the Scottish Centre for Social Research.

Contributors JWH drafted the manuscript, with contributions from all other co-authors. AHL and JWH conceived the study design with contributions from the other authors. JWH did all the analyses. JWH is guarantor. All authors had full access to all the data in the study and take full responsibility for their integrity and the accuracy of their analysis.

Provenance and peer review Not commissioned; externally peer reviewed

Data sharing statement The Scottish Health Survey datasets used in these analyses are available from the Economic and Social Data Service Data Catalogue http://www.esds.ac.uk/findingData/shlsTitles.asp. 


\section{REFERENCES}

1. Critchley JA, Capewell S, Unal B. Life-years gained from coronary heart disease mortality reduction in Scotland: prevention or treatment? J Clin Epidemiol 2003;56:583-90.

2. Muller-Nordhorn JM, Binting S, Roll S, et al. An update on regional variation in cardiovascular mortality within Europe. Eur Heart $J$ 2008;29:1316-26.

3. Hunink MG, Goldman L, Tosteson AN, et al. The recent decline in mortality from coronary heart disease, 1980-1990: the effect of secular trends in risk factors and treatment. JAMA 1997:277:535-42.

4. Capewell S, Morrison CE, McMurray JJ. Contribution of modern cardiovascular treatment and risk factor changes to the decline in coronary heart disease mortality in Scotland between 1975 and 1994 Heart 1999;81:380-6.

5. Unal B, Critchley JA, Capewell S. Explaining the decline in coronary heart disease mortality in England and Wales between 1981 and 2000. Circulation 2004;109:1101-7.

6. O'Flaherty M, Bishop J, Redpath A, et al. Coronary heart disease mortality among young adults in Scotland in relation to social inequalities: time trend study. BMJ 2009;339:b2613.

7. Wilson A, Siskind V. Coronary heart disease mortality in Australia: is mortality starting to increase among young men? Int $J$ Epidemiol 1995;24:678-84.

8. O'Flaherty M, Ford ES, Allender S, et al. Coronary heart disease trends in England and Wales from 1984 to 2004: concealed levelling of mortality rates among young adults. Heart 2008;94:178-81.

9. Ford ES, Capewell S. Coronary heart disease mortality among young adults in the US from 1980 through 2002. J Am Coll Cardiol 2007; 50:2128-32.

10. Office of the Chief Statistician. Updates to SIMD Income and Employment Domains. Edinburgh: Scottish Government, 2010. http:// www.scotland.gov.uk/Resource/Doc/933/0106194.pdf (accessed 14 Jun 2011).

11. Harald $\mathrm{K}$, Koskinen $\mathrm{S}$, Jousilahti $\mathrm{P}$, et al. Changes in traditional risk factors no longer explain time trends in cardiovascular mortality and its socioeconomic differences. J Epidemiol Community Health 2008;62:251-7.

12. Jemal A, Ward E, Anderson RN, et al. Widening of socioeconomic inequalities in US death rates, 1993-2001. PLOS ONE 2008;3: e2181.

13. Mackenbach JP, Bos V, Andersen O, et al. Widening socioeconomic inequalities in mortality in six Western European countries. Int $J$ Epidemiol 2003;32:830-7.

14. Lynch JW, Kaplan GA, Cohen RD, et al. Do cardiovascular risk factors explain the relation between socioeconomic status, risk of allcause mortality, cardiovascular mortality and acute myocardial infarction? Am J Epidemiol 1996;144:934-42.

15. Beauchamp A, Peeters A, Wolfe R, et al. Inequalities in cardiovascular disease mortality: the role of behavioural physiological and social risk factors. J Epidemiol Community Health 2010;64:542-8.

16. Bromley C, Bradshaw P, Given L, eds. The Scottish Health Survey 2008. Edinburgh: The Scottish Government, 2009. http://www scotland.gov.uk/Publications/2009/09/28102003/0 (accessed 14 Jun 2011)

17. Bromley C, Sproston K, Shelton N, eds. The Scottish Health Survey 2003. Edinburgh: The Scottish Executive, 2005. http://www.scotland. gov.uk/Publications/2005/12/02160336/03367 (accessed 14 Jun 2011).

18. Shaw A, McMunn A, Field J, eds. The Scottish Health Survey 1998. Edinburgh: The Stationery Office, 2000. http://www.sehd.scot.nhs.uk/ scottishhealthsurvey/sh8-00.html (accessed 14 Jun 2011).

19. Dong W, Erens B, eds. The Scottish Health Survey 1995. Edinburgh: The Stationery Office, 1997. http://www.archive.official-documents. co.uk/document/scottish/shealth/shhm.htm (accessed 14 Jun 2011).

20. Anon. The Lord President's Report on Action Against Alcohol Misuse. London: HMSO, 1991.

21. Bromley C, Corbett J, Erens B, et al. The Scottish Health Survey: Revised Alcohol Consumption Estimates. Edinburgh: Scottish Government, 2008. http://www.scotland.gov.uk/Resource/Doc/ 229667/0062208.pdf (accessed 14 Jun 2011).

22. Physical Activity Task Force. Let's Make Scotland More Active. A Strategy for Physical Activity. Edinburgh: Scottish Executive, 2003. http://www.scotland.gov.uk/Publications/2003/02/16324/17895 (accessed 14 Jun 2011)

23. Department of Health. At Least Five a Week: Evidence on the Impact of Physical Activity and its Relationship to Health. 2004. http://www. dh.gov.uk/en/Publicationsandstatistics/Publications/Publications PolicyAndGuidance/DH_4080994 (accessed 14 Jun 2011).

24. Rose D, Pevalin DJ. The National Statistics Socio-Economic Classification: Origins, Development and Use. Basingstoke,
Hampshire, UK: Office for National Statistics, 2005. http://www. statistics.gov.uk/methods_quality/ns_sec/downloads/NSSEC_Origins.pdf (accessed 14 Jun 2011).

25. Waterhouse J, Muir C, Correa P, et al. eds. Cancer Incidence in Five Continents. Lyon: IARC Scientific Publications, 1976.

26. Reigdor E. Measures of health inequalities: part 2. J Epidemiol Community Health 2004;58:900-3.

27. Woodward M, Oliphant J, Lowe GD, et al. Contribution of contemporaneous risk factors to social inequality in coronary heart disease and all causes mortality. Prev Med 2003;36:561-8.

28. Kanjilal S, Gregg EW, Cheng YJ, et al. Socioeconomic status and trends in disparities in 4 major risk factors for cardiovascular disease among US adults, 1971-2002. Arch Intern Med 2006;166:2348-55

29. McElduff $P$, Dobson AJ. Trends in coronary heart disease-has the socio-economic differential changed? Aust N Z J Public Health 2000;24:465-73.

30. Lee DS, Chiu M, Manuel D, et al. Trends in risk factors for cardiovascular disease in Canada: temporal, socio-demographic and geographic factors. CMAJ 2009;181:E55-66.

31. Davey Smith $G$, Hart $C L$, Hole $D$, et al. Education and occupationa social class: which is the more important indicator of mortality risk? J Epidemiol Community Health 1998;52:153-60.

32. Shewry MC, Smith WSC, Woodward M, et al. Variation in coronary risk factors by social status: results from the Scottish heart health study. Br J Gen Pract 1992;42:406-10.

33. Robinson S, Bugler C. General Lifestyles Survey 2008: Smoking and Drinking Amongst Adults. Newport: Office for National Statistics, 2010. http://www.statistics.gov.uk/downloads/theme compendia/ GLF08/GLFSmoking\&DrinkingAmongAdults2008.pdf (accessed 14 Jun 2011).

34. Anon. Smoking, Health and Social Care (Scotland) Act 2005. 2005 asp 13. Edinburgh, Scotland: Scottish Parliament, 2005.

35. Bloomfield K, Grittner U, Kramer S, et al. Social inequalities in alcoho consumption and alcohol-related problems in the study countries of the EU concerted action 'gender, culture and alcohol problems: a multinational study'. Alcohol Alcohol Suppl 2006;41:i26-36.

36. Woodward M, Shewry MC, Smith WC, et al. Social status and coronary heart disease: results from the Scottish Heart Health Study. Prev Med 1992;21:136-48.

37. Del Boca FK, Darkes J. The validity of self-reports of alcohol consumption: state of the science and challenges for research. Addiction 2003;98(Suppl 2):1-12.

38. Laaksonen M, Talala K, Martelin T, et al. Health behaviours as explanations for educational level differences in cardiovascular and all-cause mortality: a follow-up of 60000 men and women over 23 years. Eur J Public Health 2007;18:38-43.

39. Blake M, Chaudhury M, Deverill C, et al. Health Survey for England 2003: RISK Factors for Cardiovascular Disease. Norwich, 2004 http://www.dh.gov.uk/prod_consum_dh/groups/dh_digitalassets/ @dh/@en/documents/digitalasset/dh_4098911.pdf (accessed 14 Jun 2011).

40. NHS choices website. 5 A Day. http://www.nhs.uk/livewell/5aday/ Pages/5ADAYhome.aspx (accessed 14 Jun 2011).

41. Ali A, Becker E, Chaudhury M, et al. Health Survey for England 2006 Cardiovascular Disease and Risk Factors in Adults. Leeds, 2008. http://www.ic.nhs.uk/webfiles/publications/HSE06/HSE\%2006\% 20report\%20VOL\%201\%20v2.pdf (accessed 14 Jun 2011).

42. Mokdad AH, Ford ES, Bowman BA, et al. Diabetes trends in the US 1990-1998. Diabetes Care 2000;23:1278-83.

43. Anderson CA, Appel LJ, Okuda N, et al. Dietary sources of sodium in China, Japan, the United Kingdom, and the United States, women and men aged 40 to 59 years: the INTERMAP study. J Am Diet Assoc 2010;110:736-45

44. Tunstall-Pedoe $\mathrm{H}$, Connaghan J, Woodward M, et al. Pattern of declining blood pressure across replicate population surveys of the WHO MONICA project, mid-1980s to mid-1990s, and the role of medication. BMJ 2006;332:629-35.

45. Bromley C, Given L, Ormston R, eds. The Scottish Health Survey 2009. Edinburgh: The Scottish Government, 2010. http://www. scotland.gov.uk/Publications/2010/09/23154223/107 (accessed 14 Jun 2011)

46. National Center for Health Statistics. Health, United States 2010. Hyattsville, MD, 2011. http://www.cdc.gov/nchs/data/hus/hus10.pdf (accessed 14 Jun 2011).

47. Abramson $\mathrm{JH}$, Gofin $\mathrm{R}$, Habib J, et al. Indicators of social class: a comparative appraisal of measures for use in epidemiological studies. Soc Sci Med 1982;16:1739-46.

48. McFadden E, Luben R, Wareham N, et al. Occupational social class, risk factors and cardiovascular disease incidence in men and women: a prospective study in the European Prospective Investigation of Cancer and Nutrition in Norfolk (EPIC-Norfolk) cohort. Eur $J$ Epidemiol 2008;23:449-58. 
49. Tolonen H, Dobson A, Kulathinal S. Effect on trend estimates of the difference between survey respondents and non-respondents: results from 27 populations in the WHO MONICA project. Eur J Epidemiol 2005;20:887-98.

50. Lawder R, Harding O, Stockton D, et al. Is the Scottish population living dangerously? Prevalence of multiple risk factors: the Scottish Health Survey 2003. BMC Public Health 2010;10:330.

51. Sogaard AJ, Selmer R, Bjertness E, et al. The Oslo Health Study: the impact of self-selection in a large population-based survey. Int $J$ Equity Health 2004;3:3.

52. Boshuizen HC, Viet AL, Picavet HS, et al. Non-response in a survey of cardiovascular risk factors in the Dutch population: determinants and resulting biases. Public Health 2006;120:297-308.

53. Bartley M, Fitzpatrick R, Firth D, et al. Social distribution of cardiovascular disease risk factors: change among men in England 1984-1993. J Epidemiol Community Health 2000;54:806-14.

54. Schuit JA, van Loon AJM, Tijhuis M, et al. Clustering of lifestyle risk factors in a general adult population. Prev Med 2002;35:219-24.

55. Yusuf HR, Giles WH, Croft JB, et al. Impact of multiple risk factor profiles on determining cardiovascular disease risk. Prev Med 1998;27:1-9.

56. Pootinga $\mathrm{W}$. The prevalence and clustering of four major lifestyle risk factors in an English adult population. Prev Med 2007;44:124-8.

57. Marteau TM, Ogilvie D, Roland M, et al. Judging nudging: can nudging improve population health? BMJ 2001;342:263-5.

58. Power $\mathrm{C}$, Atherton $\mathrm{K}$, Strachan DP, et al. Life-course influences on health in British adults: effects of socio-economic position in childhood and adulthood. Int J Epidemiol 2007;36:532-9.
59. Lynch JW, Kaplan GA, Salonen JT. Why do poor people behave poorly? Soc Sci Med 1997;44:809-19.

60. Addor V, Wietlisbach V, Narring F, et al. Cardiovascular risk factor profiles and their social gradient from adolescence to age 74 in a Swiss region. Prev Med 2003;36:217-28.

61. Gray L, Hart CL, Smith GD, et al. What is the predictive value of established risk factors for total and cardiovascular disease mortality when measured before middle age? Pooled analyses of two prospective cohort studies from Scotland. Eur J Cardiovasc Prev Rehabil 2010;17:106-12.

62. Unal B, Critchley JA, Capewell S. Small changes in United Kingdom cardiovascular risk factors could halve coronary heart disease mortality. J Clin Epidemiol 2005;58:733-40.

63. Critchley JA, Capewell S. Substantial potential for reductions in coronary heart disease mortality in the UK through changes in risk factor levels. J Epidemiol Community Health 2003;57:243-7.

64. Unal B, Critchley JA, Capewell S. Life-years gained from modern cardiological treatments and population risk factor changes in England and Wales, 1981-2000. Am J Public Health 2005;95:103-8.

65. Capewell S, O'Flaherty M. Rapid mortality falls after risk-factor changes in populations. Lancet. Published Online First: 15 March 2011. doi:10.1016/S0140-6736(10)62302-1.

66. Critchley JA, Capewell S. Mortality risk reduction associated with smoking cessation in patients with coronary heart disease. JAMA 2003;290:86-97.

67. Commission on Social Determinants of Health. Closing the Gap in a Generation: Health Equity Through Action on the Social Determinants of Health. Final report. Geneva: WHO, 2008. http:// whqlibdoc.who.int/publications/2008/9789241563703_eng.pdf (accessed 14 Jun 2011). 